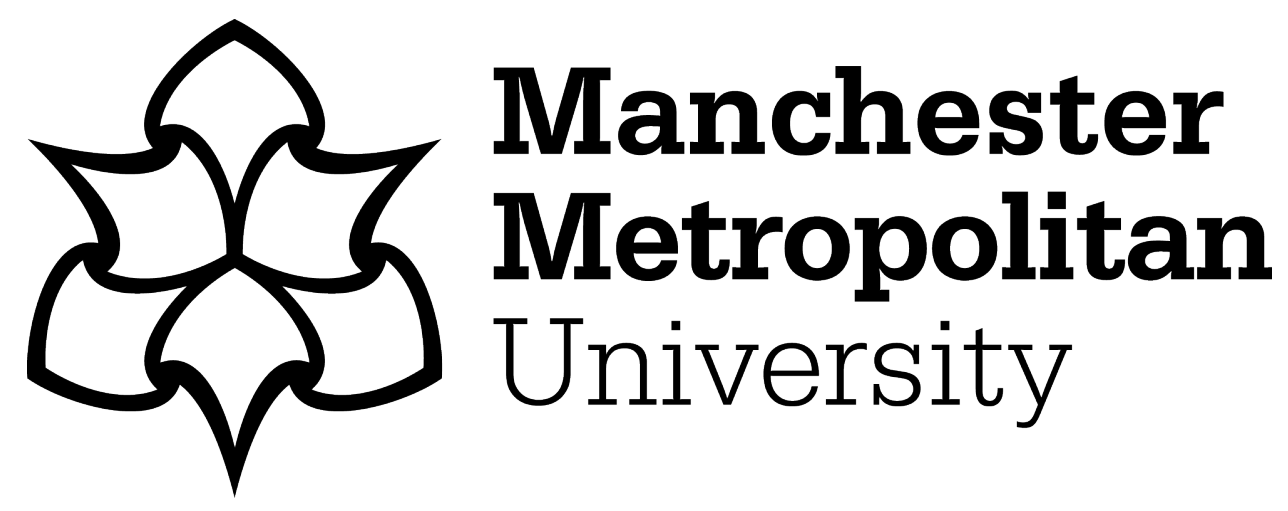

Peter, Beate ORCID logoORCID: https://orcid.org/0000-0003-4136-7733 (2013) Beyond Capital, Towards Myth: EDM Fandom and Dance Practice. In: Popular Music Fandom. Identities, Roles and Practices. Routledge Studies in Popular Music . Routledge, pp. 37-54. ISBN 978-0-415-50639-7

Downloaded from: https://e-space.mmu.ac.uk/625267/

Version: Accepted Version

Publisher: Routledge

Please cite the published version 


\section{Beyond Capital, Towards Myth: EDM Fandom and Dance Practice}

DMA: What is it that they [the French government] don't like about the parties? Is it the same as Britain or how some local governments here [America] frown upon raves?

Thomas: I don't know. They pretend it's drugs, but I don't think it's the only thing. There's drugs everywhere, but they probably wouldn't have a problem if the same thing was going on at a rock concert, because that's what they understand. They don't understand this music which is really violent and repetitive, which is house; they consider it dumb and stupid.

Thomas Bangalter of Daft Punk in Dance Music Authority Magazine (1997) ${ }^{1}$

On their 1997 album Homework, Daft Punk included a track called "Revolution 909" which began with a low bass beat, crowd noises and a sound of wailing police sirens. Over a loud hailer, official instructions came telling imagined dance fans to stop the music and go home. Hearing Daft Punk's sonic skit on the outlawing of rave offers a nostalgic reminder about the way that electronic dance music (EDM) became politicized. It raises questions: Is the practice of EDM about social inclusivity or escaping control mechanisms? Should clubbing be seen as an intrinsically meaningful activity - perhaps one geared to resist domination - or does it simply signify a particular practice? Focussing on EDM fans as dance enthusiasts, in this largely chapter I aim to fill this gap in a number of ways by reconsidering EDM theory. ${ }^{2}$ First, I will show that the internal logic and structure of fan communities can elude formulations based on capital and class. Second, drawing on the work of Papadopoulos, Stephenson and Tsianos (2008), I suggest that EDM fan cultures can be seen as "postliberal aggregates" with their own internal hierarchies. While these social formations are not intrinsically resistant, sometimes they have operated beyond State control. Third, I suggest that Joseph Campbell's (1976) work on myth may help us understand how dance itself becomes internalized as a shared subjective experience. I conclude by contextualizing this idea in relation to existing research on club cultures.

\section{Beyond Bourdieu}

For a long time in popular music studies the analysis of audiences was based on a Marxist interpretation of cultural processes. In the UK, for example, the work of the Centre for Contemporary Cultural Studies (CCCS) offered Marxist frameworks that dominated the analysis of youth cultures, subcultures, music and style. Comparative aspects of identity formation, belonging, societal relevance and fandom have been classified by dichotomous ways of thinking - as either dominant or subordinate, serious or popular - rather than placed along a continuum. For example, the CCCS was largely inspired by Gramsci's (2008) concept of "hegemony" which said that ruling alliances (historic blocs) could lead ordinary people by a process of securing popular consent. In this view, a dominant class indirectly controls the rest of society. Gramsci was primarily concerned with the lack of obvious class 
struggles within capitalist society. Although such struggles might still exist, there are, nevertheless, alternative interpretations of the functioning of society and the nation state. In recent years, those researching popular culture have attempted to move away from CCCSinspired subcultural classifications (Muggleton \& Weinzierl, 2003; Bennett \& Kahn-Harris 2004). A shift has come about, in part, because some cultural communities have been found to function on principles other than those of capital or taste. The empirical features defining such communities as class-bound have become, at least, highly blurred, so new models are required. However, it could be argued that even in recent work no new concepts have been successfully introduced that allow us to analyse popular culture without somehow harking back to capital or class.

Bourdieu's (1984) work on taste extended the notion that capital should be seen as the decisive factor in any productive cultural analysis. Writing about taste, he introduced a new terminology that has become part of the linguistic canon of sociology. "Cultural capital," "habitus" and "field" became references to social phenomena that Bourdieu identified in his study. ${ }^{3}$ Nick Prior (2011) has claimed that in studies of popular culture a "Bourdieu paradigm" developed towards the end of the 1970s based on the establishment of a body of scholarly authority, a canon of key theoretical texts, and the search empirically applicable theory. Certainly, Bourdieu's ideas about taste have been applied to the field of popular culture for a number of years. ${ }^{4}$ Yet because Bourdieu aimed to examine the discriminative processes of legitimate culture, he focused on the visual arts and modern literature at the relative expense of popular music. Popular music fans are often categorised according to genre. Music is, of course, organized into genres which are associated with different sounds, marketing, audiences and forms of social organization. To evaluate the relevance of Bourdieu's ideas, the concept a genre therefore needs to be addressed. Since genres are audibly different, musicology should be part of any discussion. Yet there is a wider context to consider as "performance situation and listening attitude connected with the sound event being studied" (Tagg 2001, 39). According to Franco Fabbri $(1999,7)$ musical genre can be defined as "a set of musical events (real or possible) whose course is governed by a definite set of socially accepted rules." In other words, shared sounds operate in relation to social contexts. On one level, these contexts are industrial as genres are product categories. In this model, Fabbri's "socially accepted rules" therefore include marketing, a cultural form that emerges from the ruling or dominant culture, not some kind of popular opposition.

Drawing on Bourdieu's work, John Fiske (1992) argued that taste discrimination applies to fan cultures. Fiske states that the operation of fan communities is based on "cultural forms that the dominant value systems denigrates" (30). Like Bourdieu, Fiske therefore associates a culture and class, at least in terms of a distinction between dominant and oppositional groupings. His idea has some applicability to fan practices in certain genres, such as heavy metal. By embedding allusions to Satanism in the system of theatrical signifiers propagated on t-shirts and recordings, "metalheadz" have been able to access feeling of belonging to an imagined community of social outsiders. Heavy metal culture symbolically reappropriates a figure that is part of Christian society. The association with Satan "expropriate[s] and 
rework[s] certain values and characteristics of that official culture to which it is opposed" (Fiske 1992, 34). However, if making theatrical allusions to Satanism could be classed as avoiding State control, authorities would strive to punish fans engaged in such practices. Belonging to an imagined community of outsiders but consuming records and live shows does not mean taking a full stance in opposition to official culture. While genre cultures are located within capitalist society, they do not have to be reduced entirely to conceptions of it. Genres are much larger than specific power struggles and social structures.

In present times, a notion of flexibility and fluidity has to be introduced to the "definite set of socially accepted rules" in order to reflect the contemporary state of social flux (see Bauman, 2003). Bourdieu's ideas were further updated by Fiske, particularly in his notion of "technostruggles" (1996, 217). Fiske argued that new technologies cannot change society, but they can be used as a means through which to initiate, further or communicate social change. This is interesting because the changing use of technologies in music practice can influence how genres are widely understood. Fiske suggests that technology is directed through "institutional and economic control" $(1996,137)$. His position assumes a political landscape in which change is difficult, where technology is used by those in power largely to oppress those without access to it. To understand technology only as an extension of the battlefield of capitalist society restricts how we can conceptualize its users. Fiske does not believe, unfortunately, that technology can be reappropriated, subverted or manipulated in ways that escape the domination / resistance dichotomy.

In changing times, audiences participate in music genres in different ways. The prospect of lifelong commitment to one subculture has now partially been replaced by the possibility of belonging to various groups. Individuals can explore their identities in more fluid ways. Maffesoli (1996) introduced the idea of "tribes" to help understand cultural groupings in contemporary society. Although his work is not yet popular in fan studies, its focus on affectual micro-groups has been connected to popular music genres. Some sociologists are starting to acknowledge that societal changes demand new models of interpretation. The restrictions exercised on subjects by nation states, for example, are not felt quite as strongly by many in a consumer-orientated postmodern world. Bourdieu's idea is modernist in that it attempts to trace one grand narrative of social structure. However, society is changing and the genres are constantly transforming. Music cultures have entered a post-Bourdieuan phase. It may be time to move away from a class or capital-based analysis of culture towards an understanding of fan communities as entities with their own internal structures and with logics, entities that cannot easily be framed by traditional theoretical dichotomies.

\section{EDM Fan Communities as Postliberal Aggregates}

While not intrinsically resistant or rebellious, certain fan cultures have operated outside of State control. In their book Escape Routes, Papadopoulos, Stephenson and Tsianos (2008) present an analysis of the political predicament of North Atlantic societies. They argue that the political subjectification of individuals or groups has become such a common practice 
precisely because it represents a successful strategy of social control. Although neoliberal society is characterised by the development of global networks, according to Papadopoulos, Stephenson and Tsianos it has failed to grant rights to the broad spectrum of political subjects. The authors therefore observe the establishment of "postliberal aggregates," contemporary social groupings with vertical power structures that escape the horizontal power structures of sovereign governance. The identification of such communities of practice has significant implications as it locates a theoretical space in which social groups can operate to escape national or transnational control mechanisms. Interestingly, escaping the control of such authorities does not mean having a total lack of power. Papadopoulos, Stephenson and Tsianos instead argue that postliberal aggregates often require new control mechanisms to be established. One example of this might be the way that Internet technology has created a new environment of potential opportunities and risks. It has become apparent that nations are struggling to control the social practice of such technology. This is not to say that consent will not be found and the Internet will never be governed, but rather that such consent, at this moment in time, is not yet fully established. One could argue that any new form of control could pose a threat to the freedom of ordinary individuals. The idea that nations will enact strict control mechanisms seems a dangerous possibility (see MacKinnon 2012). ${ }^{5}$ As a result, certain ways of using the net can be seen as lending themselves to the formation of postliberal social aggregates.

The resonance of Papadopoulos, Stephenson and Tsianos's ideas become clear when they are related to particular music genres and associated fan cultures. Punk and EDM make an interesting comparison here. At its centre, punk culture seemed to espouse a rebellious credo. Opposition to capitalist culture was articulated not only in lyrics, but also in the use of anticapitalist signifiers, public displays of resistance, and cultural practices deemed vulgar or immoral by wider society. ${ }^{6}$ Papadopoulos, Stephenson and Tsianos do not talk in any detail about music genres or fandom, but their ideas suggest that the behaviour of most fans and artists nevertheless generally support the structures of a sovereign power. ${ }^{7}$ As they state:

Sovereign power mobilises representations to organise and contain social conflict. Representation is nothing other than a means to render the forces partaking in a social conflict visible to the gaze of power. Moreover, power relations operate by making social actors representable within a regime $(2008,56)$

Their schema suggests, then, that any attempt by, say, punk fans to publically oppose the sovereign power and its dominant culture will facilitate that same power to control them. The nation state can absorb cultural conflict because it can define both the music being consumed (through supporting or censoring) and the identities of the subjects who consume it. One could argue that punk's promotion of anarchic politics, for example, might present a threat to any government. However, taking the more direct example of refusal to work, Papadopoulos, Stephenson and Tsianos (2008) note that at no point the State is truly challenged. Any transformative effect that protest or subversion might have is immediately reintegrated into the power structures by the provision of welfare. Similar processes of diffusion generally operate in relation to fan cultures and their practices. For example, while the collecting of 
memorabilia may not have been part of the original plan of mass market capitalism, Matt Hills (2002) has suggested that it cannot be seen as oppositional to official cultural practice; indeed, its focus on the importance of each star recreates and reaffirms one aspect of official culture. Equally, the positioning of punks as bricoleurs and rebels (as in Hebdige 1988) does not oppose interpretations that read its fan community as reaffirming dominant culture: "any attempt at transgression is always and inescapably contextualized and regulated by the very system or structures from which it endeavours to break away" (Gunkle and Gournelos 2012, $5)$.

The music fans participating in club culture offer a stark contrast. This group of music fans can be interpreted as a social formation escaping from wider control mechanisms by articulating "in a positive way, a not-yet represented commonality of the actors participating in a postliberal aggregate" (Papadopoulos, Stephenson and Tsianos 2008, 43). The notion of EDM fan communities as "aggregates" enables us to consider dance fandom in a different way. It changes our perspective on different kinds of fandom and also other aspects of music culture such as the reading and production of texts, the place of specific practices, and the way that specialist knowledge is accumulated and used.

Papadopoulos, Stephenson and Tsianos (2008) suggest that to avoid visibility in terms of a struggle for representation and rights the best escape routes are practices that are, as yet, unidentified as forms of escape. These everyday practices suggest a form of "imperceptible politics":

Imperceptibility is the everyday strategy which allows us to move and to act below the over-coding regime of representation. This everyday strategy is inherently antitheoretical; that is, it resists any ultimate theorisation, it cannot be reduced to one successful or necessary form of politics (such as state-oriented politics or micropolitics, for example). Rather, imperceptible politics is genuinely empiricist, that is it is always enacted as ad hoc practices which allow the decomposition of events which cannot be left unanswered by the existing regime of control (Papadopoulos, Stephenson and Tsianos 2008, 75-76).

This recognition of the contemporary relevance of everyday practice is part of a shift towards interest in what Maffesoli $(1996,1)$ identifies as puissance: the inherent energy of ordinary people. Attention to fans' everyday practices can help us avoid a discussion dominated by Marxist traditions of understanding. Because escape routes can only ever be identified in retrospect, particular music practices can sometimes be considered as such if they have been deemed controversial.

The wording of the UK's Criminal Justice and Public Order Act (1994) defined raves as gatherings at which music is played that "includes sounds wholly or predominantly characterised by the emission of a succession of repetitive beats." Such events have not disappeared from the listings of magazines, yet it has been argued that the bill's terminology primarily refers to a particular moment in history (Till 2006). While the legislative definition might explain why raves are increasingly identified as constituting a historical genre, its 
definition locates them as social episodes of emitted sound poses several problems for understanding such events.

First, the link between raving and music is a complex one. A relatively new type of music"rave" or house - became popular in the late 1980s which provided the soundtrack for a whole generation of young people. It has been documented by Rietveld (1998) and others that this music was played predominantly at raves. However, other forms of music could theoretically have been banned from being performed in such a context. In a reaction to legislation which made raves illegal, some acts produced music that could be played at them but did not conform to the defined patterns. ${ }^{8}$ Rave could not be classed as a conceptual category if defined exclusively by its sounds.

Second, therefore, raves must also be defined defined through deviant social practices. The activities most commonly associated with raves were usually classed as negative: drug use and abuse, noise pollution, trespassing, litter disposal, drug dealing, moral panic based on the realisation that drug use was not confined to the youth of a particular class, and further momentum created by the sheer number of young people participating. Because it was associated with practices that signified a deviant lifestyle, rave music became a scapegoat for the government's inability to control a new youth movement. Rather than the music itself, it is the perceived deviant cultural practices that the "anti-rave" bill aimed to suppress. The definition of rave music in British legislation was flawed because it aimed to outlaw cultural practices that could not be included in a musical definition.

Third, the way that raves are controlled, organised, structured, marketed and perceived by the public, has changed considerably since the introduction of the Criminal Justice and Public Order Act 1994. The Act marked a moment in time when the wider cultural practice related to raves actually changed. It placed raves in a political context - one that had been avoided or ignored until then. Some have argued that rave culture was actually the first youth culture to be hedonistic and apolitical at the same time. However, the Criminal Justice and Public Order Act (1994) made ravers into political subjects. Papadopoulos, Stephenson and Tsianos argue that "modern power is cynical and indifferent to morality: it is not concerned with ideological exclusion and ethical purity but with instrumental inclusion" $(2008,8)$. By framing the tendency to gather and dance as an illegal practice, the Criminal Justice bill positioned ravers as political subjects whose tendency to party, in effect, contested national sovereignty and control.

Although at the time it might not be inherently obvious that a raving youth culture were a direct threat to the nation state, the way that it responded to ravers and their the cultural practices proved that a legislative change was needed in order invalidate one potential escape route. To borrow words from Papadopoulos, Stephenson and Tsianoss $(2008,8)$, the state started including new "unruly potentialities" in its "social reproduction." Such regulation of personal and communal freedom through legislation is never an arbitrary or undirected act, but rather forms a reaction to the emergence of new social groups who can evade wider control mechanisms. Demonstrations, protests and parties were organised in the run up to the 
introduction of the Act. Campaigns were started promoting the "right" to party. The Left took on the issue by supporting a new social formation which was characterised by its desire to dance and as such placed in opposition. What is crucial to recognize here, then, is that rave was first politicized by the state, not by the ravers.

Rave music and participation in its associated culture can no longer be located within the outdated co-ordinates of mid-1990s legislation. The transition of musical terminology from rave to EDM is indicative that things have moved on since 1994. Today, dance music culture refers to a whole variety of practices that need unpacking in order to distinguish the different stakeholders in the EDM community, explain its internal functioning, and locate various stances towards state power. From a composer's or producer's point of view, the genre has become too broad to be useful in describing one particular taste, affiliation or philosophy of life. Any individual components that one can use to define the sound of EDM can be applied to various other types of music and vice versa. Almost any kind of music that provides a steady beat and is within a certain range of tempo (near heartbeat) can be matched by human movement and would qualify under the bill's outdated description.

Another way in which rave culture has changed is through shifts within the social structures of its participant communities. Papadopoulos, Stephenson and Tsianoss's (2008) notion of "postliberal aggregates" suggests that such groupings can develop their own structures and regulations. In EDM a shift in some of those elements has related to the production of music using synthesizers, drum machines and compositional software. When electronic instruments became cheaper, more individuals were able to obtain them. With the growing availability of instruments, the sounds and aesthetics of music genres have changed. The use of electronic and then digital instruments in genres whose sounds were defined by the absence of those instruments (ie. hand-made music, live music, etc) has expanded the genre palate. Some fans have seized the opportunity to become their own music producers, to change the social dynamics in their particular community, and to overturn its existing hierarchies. Furthermore, EDM has become associated with imaginative visions of a cyborgian future world in which a loss of control will mean humanity is subsequently degraded to something below a machine: an instrument or mediator of music. DJ culture forms an important context here, because in the 1980s dance DJs were already spearheading shifts in what electronic music production could do and how it was perceived (see Ferreira 2008). The transformation of DJ culture through "live" events, marketing and media coverage has promoted new cultural, social and compositional practices. Some of these practices have been adapted by artists of other genres. They have, in turn, defined new audiences and encouraged music producers to re-brand themselves in order to stay current. DJs such as Mark Ronson have become producers for albums by more traditional artists who wished for wide appeal.

Shifts in legislation have also indicated that rave culture has lost some of its attributed oppositional role. Back in the 1980s and 1990s the moral panic fuelled by the UK media focused on practices that were perceived as negative and damaging, not only to individuals but also to society. Such practices resulted in the state legislating that challenged them. By banning unlicensed outdoor raves, the state was able to control the geographic location of 
such events. It situated them in clearly defined spaces with limited access and exit points. Nightclubs could be raided. Even though a blind eye was sometimes turned to dance parties, after 1994 the state was able to instate control and power if necessary over a social formation of young people that might otherwise have escaped integration into a political structure. After the introduction of the Criminal Justice bill, nightclubs provided the sole opportunity for party-goers to consume alcohol after the $11 \mathrm{pm}$ curfew. The introduction of the new Licensing Law in 2005 meant that they lost this unique status and a significant change to night time culture then followed. Because other premises, like pubs, bars and cinema complexes, could apply for an extended license, hybrids emerged to offer new forms of night time entertainment (Mintel 2006). These mixed venues could change their interior layouts according to demand. They could provide a dance floor and seating or a cinema screen at the same time. The changing interior landscape of dance culture signifies the changing social place of the phenomenon. As "postliberal aggregates," EDM fan communities have established their own behavioural patterns, independent modes of functioning and hierarchies. They have, as such, coexisted alongside other forms of community in society.

\section{EDM Fandom: Practice, Myth and Subjectivity}

Participation in EDM culture is interesting to scholars partly because it invites us to understand the relationship between collective and subjective experience. Historically, music researchers have often represented dance cultures as forms of social collectivity. Clubbers have been seen as a small but lucrative consumer group and niche market. In order to promote specialist products, the interests of any such group must be represented to various stakeholders, whether to other fan communities, or the market if one considers the economic exploitation of fandom. Music genres have been associated in the mainstream media with particular stereotypes and canons. As the discussion of EDM, punk and heavy metal has shown, certain kinds of music and cultural practice better lend themselves to be officially identified, especially if they appear deviant or otherwise distinct from established cultural norms. However, music phenomena are composed of individual fans who assent to their worth. For many thinkers, to be valuable cultural theory should be able to offer an interpretation of individual subjectivity and the ordinary fan's production of meaning (see, for instance, McRobbie 1984; Jenkins 1992; Fitch 2001; Hills 2002). Studying popular music genres, Philip Tagg has refused to have music analysis remain part of a canon shared by a small group of people. He has begun to introduce a strain of musical analysis based on individual experience (2009), an approach that results in the analysis of music perception on a very personal level. Because Tagg's work does not fix music appreciation in relation to any particular shared musical or cultural habitus, his elevation of the individual over the social group contests the demarcation lines of Bourdieu's class-based grid of taste. EDM fans do not act, however, as isolated individuals. Relevant cultural theory needs to find a way to understand both their subjective engagement and collectivity as part of the same process. 
Dance is the most important practice in EDM fandom. It therefore deserves special attention. The practice of dancing is, of course, a much more widespread pursuit than its occurrence in EDM culture. Judith Becker (2001) interprets it as a form of active listening. Employing her view, it could be argued that as an activity it is similar to other practices of fan consumption. Although EDM scholars have primarily discussed dance in relation to genre and collective experience, the practice of moving one's body is also part of what it means to be an engaged music fan. The participatory aspect of the practice varies according to genre. Although dance is associated with many kinds of music, not all of them encourage full participation.

Stadiums, theatres and other concert venues offer seating and tend not to encourage the movement of fans' whole bodies. The lack of a clearly defined dance floor in these places has implications for how they are collectively used. At rock concerts, dancing is often defined by moves that can be executed within a limited space like head banging, jumping and stage diving. By defining a dance floor, other venues for popular music, such as Northern Soul clubs, discos and rave enclosures have actively encouraged dance. Because the visitors to such places constantly move their whole bodies, they permeate space in a different way. In the absence of staged spectacles, their dance floors can themselves become a focal point. ${ }^{9} \mathrm{~A}$ relative lack of spatial focus allows people to interact more with one another.

Because particular genres define the dance floor in different ways, their participants follow conventions of movement differently. While they might not be enforced as rigorously as law, these genre conventions form commonalities based on shared practice. At one extreme, some dances are undertaken with a partner and follow a clearly defined sequence of movements. Others celebrate individuality and free style. One way of resolving the issue of genre overlap in popular music could therefore be to include the practice of dance in order to be able to more clearly identify each type of music in terms of its association with a particular social formation. The conventions of EDM dance floors originated in the gay clubs of Chicago and New York, so the early dominance of gay dancers impacted on later understandings of body politics in the context of the genre. Rather than performing according to strictly male / female norms, the dancing body was defined through a denial of a heterosexual masculinity.

Papadopoulos, Stephenson and Tsianoss (2008) have claimed that "homosexuality unsettles the hegemonic (but vulnerable) masculine fantasy of a bounded, intact, impermeable body" (111). At early house parties, not only did the openly gay performances educate a wider audience that was drawn to the music; they also opened up opportunities for the dancing body to be used as an object capable of challenging gender norms and aesthetic conventions.

In any analysis inspired by Bourdieu's work, social formations are primarily defined on particular dance floors - as everywhere else - as using their musical tastes to display broadly equivalent levels of cultural capital through dance (see Thornton 1990; Home 1995; Garnett 1999). There are, however, other ways to understand music hearing and dance.

Neuroscientific research into the rhythmic abilities of human beings suggests that supposedly innate responses are not as static as we might have assumed (see Phillips-Silver 2008).

Because people are polyrhythmic they are therefore able to relate to a variety of rhythms and musical tastes can develop across cultural borders. Whether musical influences are 
instrumental, melodic or rhythmic, they can therefore arrive from other cultures and be incorporated in western popular music without necessarily being classified as something foreign to current tastes.

It has been argued that the EDM dance floor created a space of true social inclusivity. Discussing the Hacienda, for instance, Dave Haslam (1997, 175) claimed nostalgically, "Nobody was excluded: shop assistants, dole-ites, plasterers, thieves, students." To be inclusive means that all people participating in a nightclub or another EDM event would be encouraged to take part. Neuroscientific research into the activities of motor neurons has shown that participation cannot always be defined with regard to physical movement alone (Zatorre, 2006). When watching physical movement, the activation of certain motor regions of the brain suggests that by anticipating and imagining observers already participate in the action of dance. Their urge to join the dancers is not just a desire to be part of what Barbara Ehrenreich has called $(2007,11)$ "collective excitement," but also to perform the same physical actions as those being observed. The practice of dance can therefore be seen as a form of imitation.

One of the puzzles for those who study shared activities like dance is how people can so evidently experience them as intense subjective passions and can also engage in them as shared social pursuits. In that context defining fandom on the basis of music genre has significant limitations. A focus on dance as a fan practice suggests that a more dynamic picture of fans and their cultures can be developed. Wider studies of media fandom have begun to explore how practices draw together collective and subjective experience. Lancaster and Mikotowicz's (2001) idea of "immersion" offers a way to analyse those fan cultures based on dancing that helps us avoid limitations of the traditional text-reader dichotomy. The researchers suggest that "beneath the surface performance... is a deeper desire for the transcendent - [prompting] fans' heartfelt examination of the limits of everyday life and the need to enter otherworldly environments in order to become more than they are" (2). In the context of dance, immersion into this imaginary world has been described as a form of escape. Lancaster and Mikotowicz are primarily concerned with performance theory since the fans that they examine perform clearly defined roles and take on pre-determined characters. However, when they refer to the performance of the text as a pattern of doing that is "inscribed into the performer's body as modes of behaviour," they imply that the internal guidelines defining how each individual should interpret and enact the text may be universal $(2001,4)$. Although their notion of immersion is useful, it makes no reference to show how these internal guidelines come into existence. There is something still missing from our understanding of personal fandom's subjective dimension. If our passions emerge when we dance repeatedly, they do not simply reflect habitus or imply a search for social approval by acting tastefully. On the other hand, we can say that dance is cultivated: it is a repeatedly enacted activity that builds up an internal referential framework, but that framework that does not primarily operate as a memory to aid discrimination. I suggest that the ordering of internal modes of behaviour can be addressed by considering Joseph Campbell's model of myth. The idea of personal myth explains the subjective side of universal behaviour pattern 
because it shows that our activity is subjectively motivated and interpreted by each of us for a reason:

Certain imprints impressed upon the nervous system in the plastic period between birth and maturity are the source of many of the most widely known images of myth. Necessarily the same for all mankind, they have been variously organized in differing traditions, but everywhere function as potent energy releasers and directors. (1986, 61)

The living or re-living of mythical content might seem more obvious in parts of the world in which everyday practices include the enactment of irrational psychic content, but the process equally applies to the modern, western world. Campbell makes reference to images that represent universal ideas and how they operate as concepts which function as guides through life. His ideas can be applied to extend fan immersion as a conceptual framework, helping us to understand each fan's journey as part of both universal and individual experience. From this perspective, the fan practices that facilitate immersion are not simply forms of escape but are rather, in fact, forms of inclusion. What Lancaster and Mikotowicz describe as the fans' desires to "become more than they are" could also be interpreted as their need to explore other parts of their own minds. In other words, dance culture may allow fans to start incorporating aspects of their own psyches that are, at least in western society, suppressed.

The interpretation of dance as a practiced form of shared mythology can be connected to other work on subjectivity. One of the few relevant analyses of dance here is Angela McRobbie's (1984) piece on dance and social fantasy. McRobbie acknowledges the effect dance has on individual subjects, but she shies away from suggesting a model that could fully link it to internal processes. Although she writes about dance from a feminist perspective and is predominantly concerned with the representation of female dancers and perspectives from which they are observed, she also makes some interesting points about the social value of dance, suggesting that it is a practice primarily linked to feeling and emotion. Since such processes are generally seen as individual responses, the dance floor becomes a place allowing enchanted dancers to be "there and not there" (144). Victor Turner's concept of liminality (of being "in between") is one way to frame this state of simultaneous presence and absence. However, McRobbie's interpretation can also be used to suggest that dancers share social fantasies allowing them to resist, oppose and escape their subjective colonisation. She recognises the importance of seeing dance as engaging with "private internal processes, that is human psyches and human subjectivities" $(1984,142)$. Although this argument makes no distinction between escapism and resistance to control, it is clear that dance as a social practice avoids instrumentalisation by a sovereign power.

The relevance of McRobbie's work becomes clearer compared to Sara Thornton's (1995) application of Bourdieuan theory to club cultures. Only on occasion does Thornton (1995) make reference to the actual practice of dance. On one hand, she refers to stereotypical moves such as "headbanging, fist-raising, air-guitar solos" (71) associated with particular music genres. On the other, her methodological strategy entails being a participant observer and lets 
her conclude that dance styles can change on the dance floor according to the music played. Both McRobbie and Thornton refer to rules on the dance floor. Although McRobbie only mentions them when distinguishing between punk discos and mainstream ones, a typology of dance does not necessarily have to be artificially created. I argue that behavioural patterns on the dance floor have long been established and regularly practised as mythic unspoken traditions. Even though the EDM dance floor that has been praised as the first dance floor to be truly democratic in that it allows for all kinds of dance to be performed, it has also been shown to function within a clearly defined set of norms (Malbon 1999; Peter 2007). When discussing dance in the context of clubbing, Malbon (1999) states that it "is constituted and experienced through the dancing clubbers' techniques, competencies and spacing" (97). He goes on to say that the dancing techniques are acquired through either "through listening to and understanding the music" or through mimicry (99). By linking practice to both an understanding of the music and a set of social rules, he indicates that the social formation of dancers is one that can decode signals which are not common knowledge. This shared cultural activity is therefore based on discrimination (see Fiske 1992,35) and points towards the dancing community being understood as a kind of fan base.

McRobbie also acknowledges that "dance-as-image can only really be understood within the field of related social phenomenon" $(1984,139)$. She links dance here to youth culture, style and fashion, suggesting that beyond bodily movement other aspects require inclusion. I agree and suggest that further categories are also important in understanding dance as a social practice. First, behavioural aspects such as eye contact or tactile sensations inevitably inform each dancer's idea of bodily expression. Second, the social position of the dancing body is itself also important. This aspect includes relative placing on the dance floor (centre, edges, outside), the direction of the dance (inwards and self-focused versus outward and focused on others), and the social patterning of the dance style (one partner, many partners, no partner). Taken together, these non-verbal aspects of participation are harder to measure and record some other elements that shape how dance is understood by the dancer. ${ }^{10}$ Finally, vocal participation must also be considered. Such participation does not necessarily refer to any conversations on the dance floor, but also to acts of support or disapproval. It can range from singing along to booing or cheering.

All responses unite to produce the wider social environment of the dancer. A wide-ranging terminology exists here to describe this social environment, from "atmosphere" to "buzz, vibe, mood" (Thornton 1995, 65). St John (2009) defines the vibe as "a successful or optimum social dance-music experience, one participants are compelled to relive" (94). I argue that the vibe is created by means of communication between participating individuals and linked to individual mental processes. However, whenever these mental processes on the dance floor are discussed, they are usually criticised for their inability to extend beyond the dance floor and change everyday life (see McRobbie 1984, Malbon 1999). Considering dance as a fan practice, I argue that it does not differ so much from other practices: all of them have an impact on the everyday life of the fan. This can be explained by way of Campbell's (1976) concept of creative mythology. A mythology that incorporates the individual's personal 
experience can include the renewal and personalisation of wider traditions. As a result, creative mythology combines both the universality of myth and the personal interpretation of life experience:

Traditional mythologies, that is to say, whether of the primitive or of the higher cultures, antecede and control experience; whereas what I am calling Creative Mythology is an effect and expression of experience. Its producers do not claim divine authority for their human, all too human, works. They are not saints or priests but men and women of this world; and their first requirement is that both their works and their lives should unfold from convictions derived from their own experience.

Dance is a leisure practice that is present in cultures all around the world, in communities of all ages. Because of its omnipresence in human culture, our modern, western modes of distinction - which focus on class, gender or race - are not necessarily the best things to use to understand the practice's most immediate defining factors. Highlighting Campbell's focus on the social development of subjective experience, I suggest that EDM research might benefit from a new trajectory. I propose that dance should be understood as a fan practice and best analysed by incorporating both an internal (individual) and external (communal) approach. A new direction is called for to locate this practice as a crucial part of the identity formation process of each individual, one that shapes his or her belonging to a community of people who share a common pursuit.

\section{New Directions in EDM Fan Research}

It can be concluded from analysing different types of dance that the practice promotes joy in human beings (Ehrenreich 2007). As such, it should be celebrated as a festive ritual that is part of societal practice helping to creating identities and shared senses of belonging. In this chapter I have shown one direction that EDM research could take with regard to music-based fan communities. I demonstrated that Bourdieuan analysis can reduce our understanding of what music culture is and how it functions. To address the social developments of postliberal society, a new interpretation is necessary that departs from a purely Marxist perspective or any other form of analysis based on ahistorical assumptions of mutual cultural struggle. Evidently, cultural hierarchies do exist in most social formations. By applying Papadopoulos, Stephenson and Tsianos's (2008) notion of "postliberal aggregates," I have not denied that such hierarchies are important, but instead placed a focus on the possibility that particular practices and their associated social formations can escape the control of sovereigns powers. These aggregates' have their own internal hierarchies and power relations, but their structures and positions are no longer based on economic class or cultural capital. After becoming framed as contesting desirable social practice, as fan communities they have sometimes found themselves in political opposition. ${ }^{11}$ Any strong understanding of fandom, however, must connect macro-level activity with individual motives. Fandom research has not often considered the meaning of fandom for individual fans or how individual subjectivities 
integrate with wider, shared cultural formations. Lancaster and Mikotowicz's notion of "immersion" is one of the few attempts to discuss how fan subjectivities can operate in relation to cultural pursuits. Building on their work, I suggest that Joseph Campbell's idea of the creation of a personal myth through experience might provide a fruitful point of departure. Not only can it frame fan culture as a communal practice, but it also raises questions about how individuals form their identities in a social context of shared, mythic meanings. Although the question of how fans engage with their inner selves can never be fully answered by theory, a model that pays attention to both internal and external processes might help us to better understand their deepest motivations and drives.

\section{Bibliography}

Becker, Judith. 2001. "Anthropological Perspectives on Music and Emotion." In Music and Emotion. Theory and Research, edited by Patrick Juslin and John Sloboda, 135-160. Oxford: Oxford University Press.

Becker, Judith. 2004. Deep Listeners. Music, Emotion and Trancing. Bloomington: Indiana University Press.

Bennett, Andy and Keith Kahn-Harris. eds. 2004. After Subculture. Critical Studies in Contemporary Youth Culture. Basingstoke: Palgrave.

Bennett, Tony. et al. 2009. Culture, Class, Distinction. London: Routledge.

Bauman, Zygmunt. 2003. Liquid Love. Cambridge: Polity Press.

Bourdieu, Pierre. 1984. Distinction: A Social Critique of the Judgement of Taste. Cambridge: Harvard University Press.

Burkitt, Ian. 1991. Social Selves. Theories of the Social Formation of Personality. London: Sage.

Campbell, Joseph. 1976. The Masks of God: Creative Mythology Volume 4. London: Souvenir.

Campbell, Joseph. 1986. The Masks of God: Primitive Mythology. New York: Penguin Books.

Clayton, Martin and Rebecca Sayer and Udo Will. 2004. "In Time with Music: the Concept of Entrainment and its Significance for Ethnomusicology.” ESEM Counterpoint 1.

Colin, Mathew. 1997. Altered State: The Story of Ecstasy Culture and Acid House. London: Serpent's Tail.

Delanty, Gerard. 2003. Community. London: Routledge. 
Ehrenreich, Barbara. 2007. Dancing in the Streets: A History of Collective Joy. London: Granta Books.

Fabbri, Franco. 2007. "Browsing Music Spaces: Categories and the Musical Mind.” In Critical Essays in Popular Musicology, edited by Allan F. Moore, 1-14. Farnham: Ashgate.

Ferreira, Pedro Peixoto. 2008. "When sound meets movement: Performance in Electronic Dance Music.” Leonardo Music Journal 18:17-20.

Fiske, John. 1992. “The Cultural Economy of Fandom.” In The Adoring Audience: Fan Culture and Popular Media, edited Lisa A. Lewis, 30-44. London: Routledge.

Fiske, John. 1996. Media Matters: Everyday Culture and Political Change. Minneapolis: University of Minnesota Press.

Fiske, John. 2010 [1989]. Understanding Popular Culture. London: Routledge.

Frith, Simon. 1996. Performing Rites: One the Value of Popular Music. Oxford: Oxford University Press.

Gramsci, Antonio. 2008 [1971]. "Hegemony, Intellectuals, and the State." In Cultural Theory and Popular Culture: A Reader, edited by John Storey, 75-80. Harlow: Pearson.

Gunkle, David and Ted Gournelos. 2012. Transgression 2.0: Media, Culture and the Politics of a Digital Age. New York: Continuum.

Haslam, Dave. 1997. "DJ Culture." In The Clubcultures Reader: Readings in Popular Cultural Studies, edited by Steve Redhead, Derek Wynn and Justin O’Connor, 168-180.

Oxford: Blackwell.

Hebdige, Dick. 1988. Subculture: The Meaning of Style. London: Routledge.

Hills, Matt. 2002. Fan Cultures. London: Routledge.

Jenkins, Henry. 1992. Textual Poachers: Television Fans and Participatory Culture. London: Routledge.

Lancaster, Kurt. 2001. Fan Performances in a Media Universe: Interacting with Babylon 5. Austin: University of Texas Press.

Lancaster, Kurt and Tom Mikotowicz. eds. 2001. Performing the Force: Essays in Immersion into Science Fiction, Fantasy and Horror Environments. Jefferson: McFarland \& Company.

MacKinnon, Rebecca. 2012. Consent of the Networked: The Worldwide Struggle for Internet Freedom. New York: Basic Books.

Maffesoli, Michel. 1996. The Time of Tribes: The Decline of Individualism in Mass Society. London: Sage. 
Malbon, Ben. 1999. Clubbing: Dancing, Ecstacy and Vitality. London: Routledge.

McRobbie, Angela. 1984. "Dance and Social Fantasy." In Gender and Generation, edited by Angela McRobbie and Mica Nava, 130-161. London: MacMillan.

Mintel. 2006. "Nightclubs UK December 2006.” UK Leisure Intelligence. London: Mintel International Group Ltd.

Muggleton, David and Rupert Weinzierl. eds. 2003. The Post-Subcutures Reader. Oxford: Berg.

Papadopoulos, Dimitris, et al. 2008. Escape Routes: Control and Subversion in the $21^{\text {st }}$ Century. London: Pluto Press.

Peter, Beate. 2007. "How can we tell the dancer from the DJ? Althusser and Jung on participant roles in a nightclub setting." In History of Stardom Reconsidered, edited by Kari Kallioniemi, Kimi Kärki, Janne Mäkelä and Hannu Salmi. 149-152. Turku: International Institute for Popular Culture.

Prior, Nick. 2011. Critique and Renewal in the Sociology of Music: Bourdieu and Beyond. In Cultural Sociology 5, 1:121-138.

Rietveld, Hillegonda. 1998. This is Our House: House Music, Cultural Spaces and Technologies. Aldershot: Ashgate.

Sandvoss, Cornel. 2005. Fans: The Mirror of Consumption. Cambridge: Polity Press.

Sartore, Richard. ed. 1994. Joseph Campbell on Myth \& Mythology. Lanham (Maryland): University Press of America.

Schechner, Richard. 1998. Performance Theory. London: Routledge.

Shuker, Roy. 2005. Popular Music: The Key Concepts. London: Routledge.

St John, Graham. 2009. Technomad: Global Raving Countercultures. London: Equinox.

Storey, John. 2008. Cultural Theory and Popular Culture: An Introduction. Harlow: Pearson.

Tagg, Philip. 1982. “Analysing Popular Music: Theory, Method and Practice.” Popular Music 2: 37-65.

Tagg, Philip. 2001. "Music Analysis for Non-Musos: Popular Perception as a Basis for Understanding Musical Structure and Signification." Presented paper at Popular Music Analysis Conference, University of Cardiff, November 17.

http://www.tagg.org/xpdfs/CardiffLBH2.pdf

Thornton, Sarah. 1995. Club Cultures: Music, Media and Subcultural Capital. Cambridge: Polity Press. 
${ }^{1}$ This interview from the May 1997 issue of the magazine is reprinted online at: http://dancemusic.about.com/cs/interviews/a/IntDaftPunkDave.htm.

2 The term "fan" is defined in different places in different ways, some of which align the label with passive spectatorship. Instead, I am following the second Merriam-Webster dictionary definition: "an ardent admirer or enthusiast" (emphasis mine). See http://www.merriamwebster.com/dictionary/fan?show $=0 \& \mathrm{t}=1348058553$.

${ }^{3}$ In Bourdieu's schema, "cultural capital” is a stock of knowledge about socially valuable distinctions. The possession of this capital allows individuals to display their social status in the form of individual taste. "Habitus" is the individual's memory store of these learned predispositions. The "cultural field" is the resultant social space in which individuals assert own their particular (class bound) places.

${ }^{4}$ Thornton (1994), Becker (2004), Reynolds (2009) and Bennett (2009) apply Bourdieu's work. Phil Tagg (2001) has also referred to attitudes of performance and of listening, both of which have been situated and analysed within a Bourdieuan framework (see Becker 2001 and 2004).

${ }^{5}$ A similar scepticism is also articulated in Fiske's notion of techno struggles, when he points out that the type of media that is employed to communicate struggles can change but the struggles fundamentally remain the same.

${ }^{6}$ Punk practice, of course, has at various times included spitting, swearing, heckling, wearing Nazi symbols and sniffing glue.

${ }^{7}$ Papadopoulos, Stephenson and Tsiano $(2008,94)$ mention music in Weimar Germany in passing, but refrain from discussing it directly in the rest of their work.

${ }^{8}$ Autechre's “Anti” EP and Orbital's “Are We Here” EP are good examples of music aimed at side-stepping the he "anti-rave" bill.

${ }^{9}$ The conceptual centrality of the dance floor is, of course, complicated by the emergence of famous DJs or use of stage shows, go-go dancers or live musicians at EDM events.

${ }^{10}$ This reduces the effiveness of post hoc interviews as a research method.

${ }^{11}$ Fan bases for taboo cultural objects may also fit into this category of designated opposition. 